\title{
Families worries During the First and Second COVID-19 Wave in Germany: Comparative Longitudinal Study in Two Populational Childhood Cohorts
}

Susanne Brandstetter ( $\square$ susanne.brandstetter@ukr.de )

University Children's Hospital Regensburg (KUNO), Hospital St. Hedwig of the Order of St. John

Tanja Poulain

LIFE Child, Leipzig University

Mandy Vogel

LIFE Child, Leipzig University

Christof Meigen

LIFE Child, Leipzig University

Michael Melter

University Children's Hospital Regensburg (KUNO), Hospital St. Hedwig of the Order of St. John

Angela Köninger

University, Hospital St. Hedwig of the Order of St. John, University Medical Center Regensburg

Christian Apfelbacher

Otto von Guericke University

Wieland Kiess

LIFE Child, Leipzig University

Michael Kabesch

University Children's Hospital Regensburg (KUNO), Hospital St. Hedwig of the Order of St. John

Antje Körner

LIFE Child, Leipzig University

\section{Research Article}

Keywords: COVID-19, families, children, worries, regional differences

Posted Date: June 23rd, 2021

DOI: https://doi.org/10.21203/rs.3.rs-627406/v1

License: (c) (i) This work is licensed under a Creative Commons Attribution 4.0 International License. Read Full License 


\section{Abstract}

\section{Background}

The present study aimed to compare worries related to the Coronavirus disease 2019 (COVID-19) in families with young children in two regions in Germany differently affected by the pandemic (Regensburg in Southeast Germany, Leipzig in Eastern Germany) during the first and the second wave of the COVID-19 pandemic

Methods

720 parents participating in the KUNO Kids health study in Regensburg $(n=507)$ or the LIFE Child study in Leipzig $(n=213)$ answered questions regarding COVID-19-related worries and trust in anti-pandemic policy measures at two time points, during the first wave (spring 2020) and during the second wave (winter 2020/2021) of the pandemic. Ordinal mixed-effects models were performed to assess differences depending on region (Regensburg versus Leipzig) and time (first versus second wave), adjusting for education and migration background.

\section{Results}

Participants worried most about the general economic situation and their family and least about their own health or financial situation. Most COVID-19-related worries were stronger during the second than during the first wave. In regional comparisons, worries about family, friends, and hometown increased more pronouncedly from wave 1 to wave 2 in Leipzig than in Regensburg, paralleling the increase in SARS-CoV-2 infections. Trust in anti-pandemic policy measures, in contrast, decreased significantly between wave 1 and wave 2, with a stronger decrease in Regensburg.

\section{Conclusions}

The degree of families' COVID-19-related worries differs by region and time, which might be related to differences in infection rates and public interest.

\section{Background}

Like most European countries, Germany was hit by the COVID-19 pandemic in different waves. The first wave (spring 2020) was characterized by unevenly distributed infection rates with large areas of only a few COVID-19 cases and some hotspot regions. The second wave (winter 2020/21) affected the whole of Germany, with especially high infection rates in East Germany. During both waves, lockdown measures were implemented, including comprehensive contact restrictions and longtime closures of daycare nurseries.

Families were affected by these lockdown measures on several levels: they had to reorganize many aspects of everyday life, e.g., compensating restricted childcare, which had an impact on working conditions. Children themselves were confronted with the interruption of their familiar, daily routines and their social life [1], resulting in decreased health-related quality of life and more mental health problems [2, 3]. A previous study conducted in Germany found increased stress levels in parents during the first COVID-19 wave compared to the period before the pandemic [4]. Moreover, particularly when they had young children, they showed a stronger decrease in well-being than non-parents [5]. More than a year after the start of the COVID-19 pandemic, some people might have eventually adapted to the novel situation. On the other hand, the continuous efforts necessary to maintain family life might be considered increasingly exhaustive, causing worries, stress and compromised well-being.

Our study aimed to investigate differences in families' worries between the first and the second wave of the pandemic. By using data from two actively recruiting childhood cohorts (the KUNO Kids health study [6] and the LIFE Child study [7]) in the cities of Regensburg and Leipzig, located in the Southeast (Regensburg) and East (Leipzig) of Germany, we could shed light on the course of families' worries in two regions with considerably different COVID-19 incidences.

\section{Methods}




\section{Design}

The study adopted a longitudinal design. Data were collected through online surveys from two childhood cohorts in Germany. The cohorts are situated in Regensburg (Bavaria, Southeast of Germany) and Leipzig (Saxony, East of Germany). Compared to other German regions, Regensburg had high incidence rates during the first wave (7-day incidence (infections/100.000 inhabitants/ 7 days $)=11(15.05 .2020)$ ) but was only moderately affected during the second wave (7-day incidence $=34(01.02 .2021))$ [8] . Leipzig, in contrast, was only mildly affected by the COVID-19 pandemic during the first wave (7-day incidence $=1(15.05 .2020)$ ) but was hit hard during the second wave (7-day incidence $=193(01.02 .2021))$ [9]. Figure 1 summarizes the time trends of the COVID-19 incidences from March 2020 to April 2021 for both study regions.

Figure 1. Course of COVID-19 incidences in Bavaria (for Regensburg) and Saxony (for Leipzig) and timing of online surveys.

\section{Study participants}

The KUNO-Kids health study is an ongoing, multi-purpose birth cohort, which started in 2015 and has had 3249 participants so far [6]. The study is located in Southeast Germany and covers the city of Regensburg (approximately 170.000 inhabitants) and the adjacent, mostly rural regions. All adult mothers with basic understanding of German who are giving birth at the clinic St. Hedwig are asked to provide written informed consent for participation in the study. Only one child per family is included in the study. Data are collected immediately after the birth of the child and at various follow-ups.

The LIFE Child study is an ongoing childhood cohort study that started in 2011 and has 4800 participants so far [7]. The study is conducted in Leipzig, a city with approximately 600.000 inhabitants situated in Saxony (Eastern Germany). Participants in LIFE Child are recruited from the prenatal period until the age of 16 years and participate in annual follow-up visits. All parents provide written informed consent before participation.

All families with children aged 1.5 to 5.9 years, who were currently participating in either KUNO-Kids or LIFE Child and who had agreed to be contacted for additional studies, were eligible and contacted for the present study. In Regensburg, the invitation was sent to 1296 eligible families. Of these, 612 (50.1\%) completed the first questionnaire (wave 1) between May 7 and May 28, 2020, and 507 (82.8\% of those participating during the first wave) additionally completed the second questionnaire (second wave) between January 16 and February 10, 2021. In Leipzig, 306 of 721 eligible families (42.4\%) responded during the first wave between April 23 and Mai 9, 2020, and 213 (67.4\%) of those completed the second questionnaire (second wave) between January 18 and February 1, 2021.

The KUNO-Kids health study and the LIFE Child study were designed in accordance with the Declaration of Helsinki. The KUNOKids study was approved by the Ethics Committee of the University of Regensburg (Reference Number 14-101-0347). The LIFE Child study was approved by the Ethics Committee of the Medical Faculty of the Leipzig University (Reg. No. 264/10-ek). All participants were informed on the study content and provided informed written consent before participation in the KUNO-kids study or the LIFE Child study.

\section{Questionnaire}

The survey covered the same questions at both time points. Topics included SARS-CoV-2 infections among family members or friends, risk persons among family and friends, current quarantine status, current working situation, trust in anti-pandemic policy measures and various COVID-19-related worries (see Additional file 1).

For both cohorts, the survey data were complemented by information on the age of mother and child, migration background, highest educational level and employment status of both parents, and the child's nursery or kindergarten attendance.

\section{Statistical analyses}

All analyses were performed using R version 4.0 [10]. Categorical and ordinal data are reported as frequencies and percentages, continuous data as means and ranges. 
Associations between COVID-19-related worries and trust in anti-pandemic policy measures (ordered ordinal scaled outcomes) and time (wave 2 versus wave 1), region (Leipzig versus Regensburg), and interactions between time and region were analyzed using ordinal mixed-effects models [11], with the subject included as random effect. Effects were presented as odds ratios (ORs) together with $95 \%$ confidence intervals (Cls). Interactions between time and region were included if the interaction term reached statistical significance $(p<.05)$. All analyses were adjusted for education and migration background.

\section{Results}

Sociodemographic and pandemic-related information on the study participants are displayed in Table 1. The sample was characterized by a high socio-economic status, reflected in high rates of employment (employment of both parents: 57\% (Leipzig) - 62\% (Regensburg)), high rates of families with at least one parent with university entrance level (79\% (Regensburg) - 85\% (Leipzig)), and a low rate of migration background (3\% (Leipzig) - 10\% (Regensburg)). The percentage of persons in quarantine $(1-2 \%)$ was negligible in both cities and at both time points. The majority of participants (> $84 \%)$ knew at least one person at risk. This percentage was highest at wave 2 in Regensburg (96\%). The percentages of participants knowing persons infected with COVID-19 increased dramatically from wave 1 (20\%) to wave 2 (67\%). At wave 1, this percentage was higher in Regensburg (23\%) than in Leipzig (13\%). At wave 2, in contrast, the percentage was slightly higher in Leipzig (70\%) than in Regensburg (65\%). In both regions, most families (about 60\%) stated that at least one parent worked from home more often than before the pandemic.

Table 1. Characteristics of the study populations in Regensburg and Leipzig at wave 1 and wave 2 of the COVID-19 pandemic 


\begin{tabular}{|c|c|c|c|c|c|}
\hline & & \multicolumn{2}{|c|}{ Regensburg ( $n=507$ ) } & \multicolumn{2}{|c|}{ Leipzig ( $n=213$ ) } \\
\hline & & w 1 & w 2 & w 1 & w 2 \\
\hline \multicolumn{6}{|l|}{ Sociodemographic information } \\
\hline \multirow[t]{2}{*}{ Age mother at wave 1} & \multirow[t]{2}{*}{ Mean (range) } & \multirow{2}{*}{\multicolumn{2}{|c|}{$\begin{array}{l}36 \text { years } \\
\text { (25-48 years) }\end{array}$}} & \multirow{2}{*}{\multicolumn{2}{|c|}{$\begin{array}{l}35 \text { years } \\
\text { (22-50 years) }\end{array}$}} \\
\hline & & & & & \\
\hline \multirow{2}{*}{$\begin{array}{l}\text { Age child } \\
\text { at wave } 1\end{array}$} & \multirow[t]{2}{*}{ Mean (range) } & \multicolumn{2}{|l|}{3.4 years } & \multicolumn{2}{|l|}{3.7 years } \\
\hline & & \multicolumn{2}{|l|}{ (1.7-4.9 years) } & \multicolumn{2}{|c|}{ (1.5-5.9 years) } \\
\hline \multirow[t]{3}{*}{ Child in kindergarten } & Yes & \multicolumn{2}{|l|}{$334(66 \%)$} & \multicolumn{2}{|l|}{$133(62 \%)$} \\
\hline & No & \multicolumn{2}{|l|}{$148(29 \%)$} & \multicolumn{2}{|l|}{38 (18\%) } \\
\hline & Missing & \multicolumn{2}{|l|}{$25(5 \%)$} & \multicolumn{2}{|l|}{$42(20 \%)$} \\
\hline \multirow[t]{4}{*}{ Employment status parents } & Both employed & \multicolumn{2}{|l|}{$316(62 \%)$} & \multicolumn{2}{|l|}{$122(57 \%)$} \\
\hline & One employed & \multicolumn{2}{|l|}{$159(31 \%)$} & \multicolumn{2}{|l|}{$66(31 \%)$} \\
\hline & Both unemployed & \multicolumn{2}{|l|}{$4(1 \%)$} & \multicolumn{2}{|l|}{$7(3 \%)$} \\
\hline & Missing & \multicolumn{2}{|l|}{$28(6 \%)$} & \multicolumn{2}{|l|}{$18(8 \%)$} \\
\hline \multirow[t]{3}{*}{ Education $^{\mathrm{a}}$} & Higher & \multicolumn{2}{|l|}{$400(79 \%)$} & $180(85 \%)$ & \\
\hline & Lower & $105(21 \%)$ & & $32(15 \%)$ & \\
\hline & Missing & $2(<1 \%)$ & & $1(<1 \%)$ & \\
\hline Migration background ${ }^{\mathrm{b}}$ & Yes & $53(10 \%)$ & & $7(3 \%)$ & \\
\hline & No & $441(87 \%)$ & & $154(72 \%)$ & \\
\hline & Missing & $13(3 \%)$ & & $42(20 \%)$ & \\
\hline Pandemic-related information & & & & & \\
\hline Currently in quarantine & Yes & $2(<1 \%)$ & $6(1 \%)$ & $5(2 \%)$ & $5(2 \%)$ \\
\hline & No & $505(100 \%)$ & $501(99 \%)$ & $208(98 \%)$ & $208(98 \%)$ \\
\hline Person at risk in family/circle of friends & Yes & $429(85 \%)$ & $488(96 \%)$ & $179(84 \%)$ & $184(86 \%)$ \\
\hline & No & $78(15 \%)$ & $19(4 \%)$ & $34(16 \%)$ & $29(14 \%)$ \\
\hline Infection in family/circle & Severe & $49(9 \%)$ & $102(20 \%)$ & $10(5 \%)$ & $46(22 \%)$ \\
\hline of friends & Mild & $69(14 \%)$ & $230(45 \%)$ & $18(8 \%)$ & $102(48 \%)$ \\
\hline & No & $389(77 \%)$ & $175(35 \%)$ & $185(87 \%)$ & $65(30 \%)$ \\
\hline Change in working situation ${ }^{c}$ & No change & $185(36 \%)$ & & $85(40 \%)$ & \\
\hline & More home office & $304(60 \%)$ & & $128(60 \%)$ & \\
\hline & Missing & $18(4 \%)$ & & $0(0 \%)$ & \\
\hline
\end{tabular}

wh wave

ahigher: university entrance level of mother or father; lower: no university entrance level of mother and father

${ }^{b}$ defined as one or both parents with migration background

${ }^{c}$ defined as one or both parents working from home more often than before the pandemic 
The percentage of participants stating strong to extreme COVID-19-related worries and trust in the anti-pandemic policy measures in Regensburg and Leipzig at wave 1 and wave 2 are shown in Figure 2. In both regions, participants worried most about the economy and least about themselves and their financial situation. Trust in anti-pandemic policy measures was high, especially in Regensburg.

Table 2 presents the effects of time and region on COVID-19-related worries and trust in anti-pandemic policy measures. While worries about the world, the economy, and one's own financial situation decreased significantly from wave 1 to wave 2 , worries about oneself and one's own country increased. Worries about family, friends, and the hometown also increased significantly, with a significantly higher increase in Leipzig than in Regensburg. Regarding further differences between Leipzig and Regensburg, the participants worried significantly less about themselves and the world in Leipzig than in Regensburg. With respect to trust in antipandemic policy measures, we observed a significant decrease from wave 1 to wave 2 in Regensburg, but no significant change in Leipzig, where it was already low in the first wave.

Table 2. Effects of Time (wave 1 versus wave 2) and Region (Leipzig versus Regensburg) on COVID-19-related worries and trust in policy measures 


\begin{tabular}{|c|c|c|c|c|c|c|}
\hline & \multicolumn{3}{|c|}{ Main effects only } & \multicolumn{3}{|c|}{ Significant interaction Time*Region } \\
\hline & & $\begin{array}{l}\text { Effect Region } \\
\text { (L vs. RB) }\end{array}$ & $\begin{array}{l}\text { Effect Time } \\
\text { (w } 2 \text { vs. w } 1 \text { ) }\end{array}$ & $\begin{array}{l}\text { Effect Time } \\
\text { in } \\
\text { Regensburg }\end{array}$ & $\begin{array}{l}\text { Effect } \\
\text { Time } \\
\text { in Leipzig }\end{array}$ & $\begin{array}{l}\text { p-value } \\
\text { difference }\end{array}$ \\
\hline \multirow[t]{3}{*}{ Worries about own person } & OR & 0.47 & 2.08 & ns & & \\
\hline & $\mathrm{Cl}$ & $\begin{array}{l}(0.31- \\
0.72)\end{array}$ & $(1.66-2.60)$ & & & \\
\hline & $\mathrm{P}$ & $<.001$ & $<.001$ & & & \\
\hline \multirow[t]{3}{*}{ Worries about family } & OR & & & 1.38 & 3.01 & \\
\hline & $\mathrm{Cl}$ & & & $\begin{array}{l}(1.08- \\
1.78)\end{array}$ & $\begin{array}{l}(1.93- \\
4.71)\end{array}$ & \\
\hline & $P$ & & & $<.05$ & $<.001$ & $<.001$ \\
\hline \multirow[t]{3}{*}{ Worries about friends } & OR & & & 1.72 & 2.97 & \\
\hline & $\mathrm{Cl}$ & & & $\begin{array}{l}(1.33- \\
2.21)\end{array}$ & $\begin{array}{l}(1.90- \\
4.67)\end{array}$ & \\
\hline & $\mathrm{P}$ & & & $<.001$ & $<.001$ & $<.01$ \\
\hline \multirow[t]{3}{*}{ Worries about hometown } & OR & & & 1.47 & 2.67 & \\
\hline & $\mathrm{Cl}$ & & & $\begin{array}{l}(1.15- \\
1.88)\end{array}$ & $\begin{array}{l}(1.71- \\
4.19)\end{array}$ & \\
\hline & $P$ & & & $<.01$ & $<.001$ & $<.05$ \\
\hline \multirow[t]{3}{*}{ Worries about country } & OR & 0.76 & 1.54 & ns & & \\
\hline & $\mathrm{Cl}$ & $\begin{array}{l}(0.54- \\
1.06)\end{array}$ & $(1.25-1.90)$ & & & \\
\hline & $P$ & .108 & $<.001$ & & & \\
\hline \multirow[t]{3}{*}{ Worries about world } & OR & 0.64 & 0.80 & ns & & \\
\hline & $\mathrm{Cl}$ & $(0.43-0.95)$ & $\begin{array}{l}(0.65- \\
0.99)\end{array}$ & & & \\
\hline & $\mathrm{P}$ & $<.05$ & $<.05$ & & & \\
\hline \multirow[t]{3}{*}{ Worries about economy } & OR & 0.76 & 0.74 & ns & & \\
\hline & $\mathrm{Cl}$ & $(0.52-1.11)$ & $\begin{array}{l}(0.60- \\
0.92)\end{array}$ & & & \\
\hline & $P$ & .159 & $<.01$ & & & \\
\hline \multirow{3}{*}{$\begin{array}{l}\text { Worries about own financial } \\
\text { situation }\end{array}$} & OR & 0.82 & 0.54 & ns & & \\
\hline & $\mathrm{Cl}$ & $(0.49-1.35)$ & $\begin{array}{l}(0.43- \\
0.68)\end{array}$ & & & \\
\hline & $P$ & .430 & $<.001$ & & & \\
\hline \multirow[t]{3}{*}{ Trust in policy measures } & OR & & & 0.30 & 0.91 & \\
\hline & $\mathrm{Cl}$ & & & $\begin{array}{l}(0.22- \\
0.39)\end{array}$ & $\begin{array}{l}(0.59- \\
1.41)\end{array}$ & \\
\hline & $P$ & & & $<.001$ & .689 & $<.001$ \\
\hline
\end{tabular}


Interaction terms are only presented in the case of significance $(p<.05)$. In the case of significant interactions between Time and Region, main effects should not be interpreted and, therefore, are not presented.

All associations are adjusted for education and migration.

$\mathrm{w}=$ wave; $\mathrm{ns}=$ not significant; $\mathrm{OR}=$ odds ratio $\mathrm{Cl}=95 \%$ confidence interval

\section{Discussion}

The present longitudinal online study investigated COVID-19-related worries in families with young children during the first (spring 2020) and second (winter 2020/2021) waves in two regions in Germany (Regensburg and Leipzig) that have been affected differently by the pandemic. The online surveys were completed by parents of 1.5 - to 5 -year-old children, i.e., by individuals who often suffered from a double burden during the pandemic (work and caring for children at home) [12, 13]. Indeed, $60 \%$ of our study sample reported switching to home office because of the pandemic.

Overall, study participants worried most about the possible impact of the pandemic on the economy. They also worried about the situation in the world or their country. These worries might be explained by the financial crisis $[14,15]$ and the omnipresence of the economic consequences related to the pandemic (through media reports, closed businesses, knowledge of acquaintances who lost their job or are on short-time work). In contrast, the worries about their own financial situation were comparably low. One reason for this discrepancy might be the low proportion of people with migration background and the large proportion of people with higher education, indicating a high socio-economic status of the study participants. In higher social strata, people are more likely to have stable jobs and financial reserves and, therefore, suffer less from the pandemic-related financial crisis [16].

Regarding worries about themselves and close relatives, study participants worried most about family members and least about themselves. Worries about family members might particularly reflect worries about (grand) parents, as older people are at higher risk for severe or even fatal illness relating to COVID-19 than younger people [17]. The low level of worries about themselves might be explained by the higher social status in the present sample, as people from higher social classes are at lower risk for health risks at work [16]. The finding might also reflect a perceived resilience to infection or a strong belief to recover quickly if infected, e.g., because one does not belong to a risk group [18] or follows a healthy lifestyle [19].

\section{Changes of worries from the first to the second wave and regional differences}

Our analyses showed that most COVID-19-related worries assessed in the present study increased from the first to the second wave. This increase was particularly strong for worries referring to participants themselves or their immediate vicinity (family, friends, hometown). In the spring of 2020, many people still assumed that the virus would not affect their lives in the long term. By the winter of 2020/2021, however, it had become clear that the virus had spread further, with considerable mortality. The 7-day incidence was also higher during the second wave (34/100.000 and 193/100.000 inhabitants/week in Regensburg and Leipzig, respectively $[8,9])$ than during the first wave $(11 / 100.000$ and $1 / 100.000$ inhabitants/week), as was the number of infected people in the circle of acquaintances ( $70 \%$ and $65 \%$ during wave 2 versus $23 \%$ and $13 \%$ during wave 2 ) in the present sample. Therefore, the increase in worries from the first to the second wave might reflect the increase in actual infections and the higher visibility of the pandemic. This assumption is in line with findings from other studies investigating the general population. An Austrian study showed lower wellbeing and higher stress levels during the first COVID-19-related lockdown, when infection rates were high, than six months later, when infection rates were low [20]. A study conducted in Germany also found a significant decline in wellbeing from the first to the second wave [21]. The authors also observed a decrease in safety behavior and, therefore, interpreted the findings as pandemic fatigue (rather than increased own concern).

Interestingly, for some worries, namely worries about family members, friends, and the hometown, the increase from the first to the second wave was stronger in Leipzig than in Regensburg. This finding might be explained by the higher increase in the number of infections in Leipzig. Taken together, the variations in worries between different time points or different study regions might be 
explained by (the development of) the regional incidence of infections and, related to this, one's confrontation with the virus or the pandemic. This is in line with findings from a Germany-wide study that revealed regional differences in people's mental health according to infection rates [22].

For worries about oneself and worries about the world, we observed a constantly lower level of worries in Leipzig than in Regensburg, which is hardly explainable by the course of the pandemic only. General differences in mentality between the two regions could play a role here; however, these differences are beyond the scope of this study.

Regarding trust in anti-pandemic policy measures, our analyses showed a moderately high level of trust, which, however, was significantly lower during the second than during the first wave. These findings are in line with studies conducted in Germany [23, 24] and Austria [25], according to which people's acceptance of measures and trust in the scientific basis for measures decreased significantly from summer 2020 to winter 2021. The decrease in trust observed in our study might reflect families' dissatisfaction or lack of understanding in the face of constantly changing restriction measures and relaxations. For example, the rules for closure or opening of nurseries have changed continuously, impeding families' organization of everyday life. The public debate about adequate safety measures in childcare facilities was marked by controversies, and the actual implementation of safety measures differed between different regions of Germany.

\section{Strengths and limitations}

We have learned during the COVID-19 pandemic that infection rates and associated anti-pandemic policy measures are rapidly changing and can vary greatly from region to region. Our study acknowledges this variability by investigating large samples from two regions in Germany at two time points and allows for a close look at parents' worries during the COVID-19 pandemic. A limitation of our study is that the study population consisted mostly of well educated parents as we drew them from our ongoing pediatric cohort studies. As with most studies relying on active participation [26, 27], families with low education, low income, and migration background were underrepresented. Due to this selection bias, we may underestimate the impact of the pandemic on families who are underprivileged. On the other hand, people who were more concerned about the pandemic or who considered the pandemic a topic relevant to be investigated might have been more prone to participate in the present surveys. Further, although studying two time points and two study regions, we cannot differentiate between effects caused by differences in the course of the pandemic or the associated policy measures or by differences of the two regions. Also, residual confounding cannot be excluded.

\section{Conclusions}

Families' COVID-19-related worries and their trust in anti-pandemic policy measures changed during the course of the pandemic and differed between the study regions. The extent to which worries or trust were expressed might depend on regional infection rates and the associated salience of the pandemic and the anti-pandemic policy measures.

\section{Abbreviations}

COVID-19 - Coronavirus disease 2019

\section{Declarations}

\section{Ethics approval and consent to participate}

The KUNO-Kids health study and the LIFE Child study were designed in accordance with the Declaration of Helsinki. The KUNOKids study was approved by the Ethics Committee of the University of Regensburg (Reference Number 14-101-0347). The LIFE Child study was approved by the Ethics Committee of the Medical Faculty of the Leipzig University (Reg. No. 264/10-ek). All study participants were adults and provided informed written consent before participation in the KUNO-kids study or the LIFE Child study.

\section{Consent for publication}


Not applicable

\section{Availability of data and material}

De-identified participant data of the KUNO Kids study will be made available upon reasonable request from MK. Data of the LIFE Child study cannot be shared publicly because the data contains potentially sensitive information and publishing data sets is not covered by the informed consent provided by the study participants. Researchers interested in accessing and analyzing data collected in the LIFE Child study may contact the data use and access committee (forschungsdaten@medizin.uni-leipzig.de).

\section{Competing interests}

The authors declare that they have no competing interests.

\section{Funding}

The KUNO-Kids study is funded by research grants of the EU (HEALS: 603946) and the German Federal Ministry for Education and Research (SYSINFLAME: 01ZX1306E). Further financial support was provided by the University Children's Hospital Regensburg (KUNO) and the Hospital St. Hedwig of the order of St. John. The LIFE Child study is funded by means of the European Union, by means of the European Social Fund (ESF), by the European Regional Development Fund (ERDF), and by means of the Free State of Saxony as per the budget approved by the state parliament.

\section{Authors' contributors}

SB, TP, MV, MK, and AKörner designed the study. SB, MV, CA, AKöninger, WK and MM contributed to data collection. TP, MV, and $\mathrm{CM}$ analysed the data. SB and TP drafted the first version of the manuscript. All authors contributed to interpretation of data and critical revision of the manuscript. All authors read and approved the final manuscript.

\section{Acknowledgements}

We thank all families for their participation and the teams of LIFE Child and KUNO kids. We acknowledge support from Leipzig University for Open Access Publishing.

The members of the KUNO Kids study group are: Andreas Ambrosch (Institute of Laboratory Medicine, Microbiology and Hygiene, Barmherzige Brüder Hospital, Regensburg, Germany), Petra Arndt (ZNL Transfercenter of Neuroscience and Learning, University of Ulm, Ulm, Germany), Andrea Baessler (Department of Internal Medicine II, Regensburg University Medical Center, Regensburg, Germany), Mark Berneburg (Department of Dermatology, University Medical Centre Regensburg, Regensburg, Germany), Stephan Böse-O’Reilly (University Children's Hospital Regensburg (KUNO), Hospital St. Hedwig of the Order of St. John, Regensburg, Germany), Romuald Brunner (Clinic of Child and Adolescent Psychiatry, Psychosomatics and Psychotherapy, Bezirksklinikum Regensburg (medbo), Regensburg, Germany), Wolfgang Buchalla (Department of Conservative Dentistry and Periodontology, University Hospital Regensburg, University of Regensburg, Regensburg, Germany), Sara Fill Malfertheiner (Clinic of Obstetrics and Gynecology St. Hedwig, University of Regensburg, Regensburg, Germany), André Franke (Institute of Clinical Molecular Biology, Christian-Albrechts-University of Kiel, Kiel, Germany), Sebastian Häusler (Clinic of Obstetrics and Gynecology St. Hedwig, University of Regensburg, Regensburg, Germany), Iris Heid (Department of Genetic Epidemiology, University of Regensburg, Regensburg, Germany), Caroline Herr (Bavarian Health and Food Safety Authority (LGL), Munich, Germany), Wolfgang Högler (Department of Pediatrics and Adolescent Medicine, Johannes Kepler University Linz, Linz, Austria), Sebastian Kerzel (Division of Pediatric Pneumology and Allergy, University Children's Hospital Regensburg (KUNO), Hospital St. Hedwig of the Order of St. John, Regensburg, Germany), Michael Koller (Center for Clinical Studies, University Hospital Regensburg, Regensburg, Germany), Michael Leitzmann (Department of Epidemiology and Preventive Medicine, University of Regensburg, Regensburg, Germany), David Rothfuß (City of Regensburg, Coordinating Center for Early Interventions, Regensburg, Germany), Wolfgang Rösch (Department of Pediatric Urology, University Medical Center, Regensburg, Germany), Bianca Schaub (Pediatric Allergology, Department of Pediatrics, Dr. von Hauner Children's Hospital, University Hospital, LMU Munich, Munich, Germany), Bernhard H.F. Weber (Institute of Human Genetics, University of Regensburg, Regensburg, Germany), Stephan Weidinger (Department of Dermatology, Venereology and Allergy, University Hospital Schleswig-Holstein, Campus Kiel, Kiel, Germany) and Sven Wellmann 
(Division of Neonatology, University Children's Hospital Regensburg (KUNO), Hospital St. Hedwig of the Order of St. John, Regensburg, Germany).

\section{References}

1. Poulain T, Meigen C, Sobek C, Ober P, Igel U, Körner A, et al. Loss of childcare and classroom teaching during the Covid-19related lockdown in spring 2020: A longitudinal study on consequences on leisure behavior and schoolwork at home. PloS One. 2021;16:e0247949.

2. Ravens-Sieberer U, Kaman A, Erhart M, Devine J, Schlack R, Otto C. Impact of the COVID-19 pandemic on quality of life and mental health in children and adolescents in Germany. Eur Child Adolesc Psychiatry. 2021;1-11.

3. Vogel M, Meigen C, Sobek C, Ober P, Igel U, Körner A, et al. Well-being and COVID-19-related worries of German children and adolescents: A longitudinal study from pre-COVID to the end of lockdown in Spring 2020. JCPP Adv. 2021;e12004-e12004.

4. Calvano C, Engelke L, Di Bella J, Kindermann J, Renneberg B, Winter SM. Families in the COVID-19 pandemic: parental stress, parent mental health and the occurrence of adverse childhood experiences-results of a representative survey in Germany. Eur Child Adolesc Psychiatry. 2021;1-13.

5. Huebener M, Waights S, Spiess CK, Siegel NA, Wagner GG. Parental well-being in times of Covid-19 in Germany. Rev Econ Househ. 2021;1-32.

6. Brandstetter S, Toncheva AA, Niggel J, Wolff C, Gran S, Seelbach-Göbel B, et al. KUNO-Kids birth cohort study: rationale, design, and cohort description. Mol Cell Pediatr. 2019;6:1.

7. Poulain T, Baber R, Vogel M, Pietzner D, Kirsten T, Jurkutat A, et al. The LIFE Child study: a population-based perinatal and pediatric cohort in Germany. Eur J Epidemiol. 2017;32:145-58.

8. Bavarian Health and Food Safety Authority (LGL).

https://www.lgl.bayern.de/gesundheit/infektionsschutz/infektionskrankheiten_a_z/coronavirus/karte_coronavirus/index.htm. Accessed 6 May 2021.

9. infection cases in Saxony. https://www.coronavirus.sachsen.de/infektionsfaelle-in-sachsen-4151.html. Accessed 6 May 2021.

10. R Core Team. R: A language and environment for statistical computing. R Foundation for Statistical Computing, Vienna, Austria. URL https://www.R-project.org/. 2017.

11. Christensen RHB. Ordinal-Regression Models for Ordinal Data. R package version 2019. 2019. https://CRAN.Rproject.org/package=ordinal.

12. Power K. The COVID-19 pandemic has increased the care burden of women and families. Sustain Sci Pract Policy. 2020;16:67-73.

13. Kreyenfeld M, Zinn S. Coronavirus and care: How the coronavirus crisis affected fathers' involvement in Germany. Demogr Res. 2021;44:99-124.

14. Anderton R, Botelho V, Consolo A, Da Silva AD, Foroni C, Mohr M, et al. The impact of the COVID-19 pandemic on the euro area labour market. Econ Bull Artic. 2021;8. https://ideas.repec.org/a/ecb/ecbart/202100082.html. Accessed 28 Apr 2021.

15. Padhan R, Prabheesh KP. The economics of COVID-19 pandemic: A survey. Econ Anal Policy. 2021;70:220-37.

16. Holst H, Fessler A, Niehoff S. Covid-19, social class and work experience in Germany: inequalities in work-related health and economic risks. Eur Soc. 2021;23:S495-512.

17. Parohan M, Yaghoubi S, Seraji A, Javanbakht MH, Sarraf P, Djalali M. Risk factors for mortality in patients with Coronavirus disease 2019 (COVID-19) infection: a systematic review and meta-analysis of observational studies. Aging Male.

2021;23:1416-24.

18. Giordani RCF, Zanoni da Silva M, Muhl C, Giolo SR. Fear of COVID-19 scale: Assessing fear of the coronavirus pandemic in Brazil. J Health Psychol. 2020;1359105320982035.

19. Nguyen HT, Do BN, Pham KM, Kim GB, Dam HTB, Nguyen TT, et al. Fear of COVID-19 scale-associations of Its scores with health literacy and health-related behaviors among medical students. Int J Environ Res Public Health. 2020;17:4164.

Page $11 / 13$ 
20. Pieh C, Budimir S, Humer E, Probst T. Comparing mental health during the COVID-19 lockdown and 6 months after the lockdown in Austria: a longitudinal study. Front Psychiatry. 2021;12. doi:10.3389/fpsyt.2021.625973.

21. Moradian S, Bäuerle A, Schweda A, Musche V, Kohler H, Fink M, et al. Differences and similarities between the impact of the first and the second COVID-19-lockdown on mental health and safety behaviour in Germany. J Public Health. 2021. doi:10.1093/pubmed/fdab037.

22. Peters A, Rospleszcz S, Greiser KH, Dallavalle M, Berger K, Complete list of authors available under: Collaborators. The impact of the COVID-19 pandemic on self-reported health. Dtsch Arzteblatt Int. 2020;117:861-7.

23. Betsch C, Wieler L, Bosnjak M, Ramharter M, Stollorz V, Omer S, et al. Germany COVID-19 Snapshot MOnitoring (COSMO Germany): Monitoring knowledge, risk perceptions, preventive behaviours, and public trust in the current coronavirus outbreak in Germany. 2020. doi:10.23668/psycharchives.2776.

24. Trust in institutions (COSMO). https://projekte.uni-erfurt.de/cosmo2020/web/topic/vertrauen-ablehnung-demos/10vertrauen/\#vertrauen-in-die-regierung-im-detail-stand-23.03.21. Accessed 11 May 2021.

25. Heinz J, Ogris G. Freiheitsindex Österreich 2020. Follow-up 2021. 2021;:38.

26. Grosser A, Razum O, Vrijkotte TGM, Hinz I-M, Spallek J. Inclusion of migrants and ethnic minorities in European birth cohort studies-a scoping review. Eur J Public Health. 2016;26:984-91.

27. Lange M, Butschalowsky HG, Jentsch F, Kuhnert R, Schaffrath Rosario A, Schlaud M, et al. [The first KigGS follow-up (KiGGS Wave 1): study conduct, sample design, and response]. Bundesgesundheitsblatt Gesundheitsforschung Gesundheitsschutz. 2014;57:747-61.

\section{Figures}

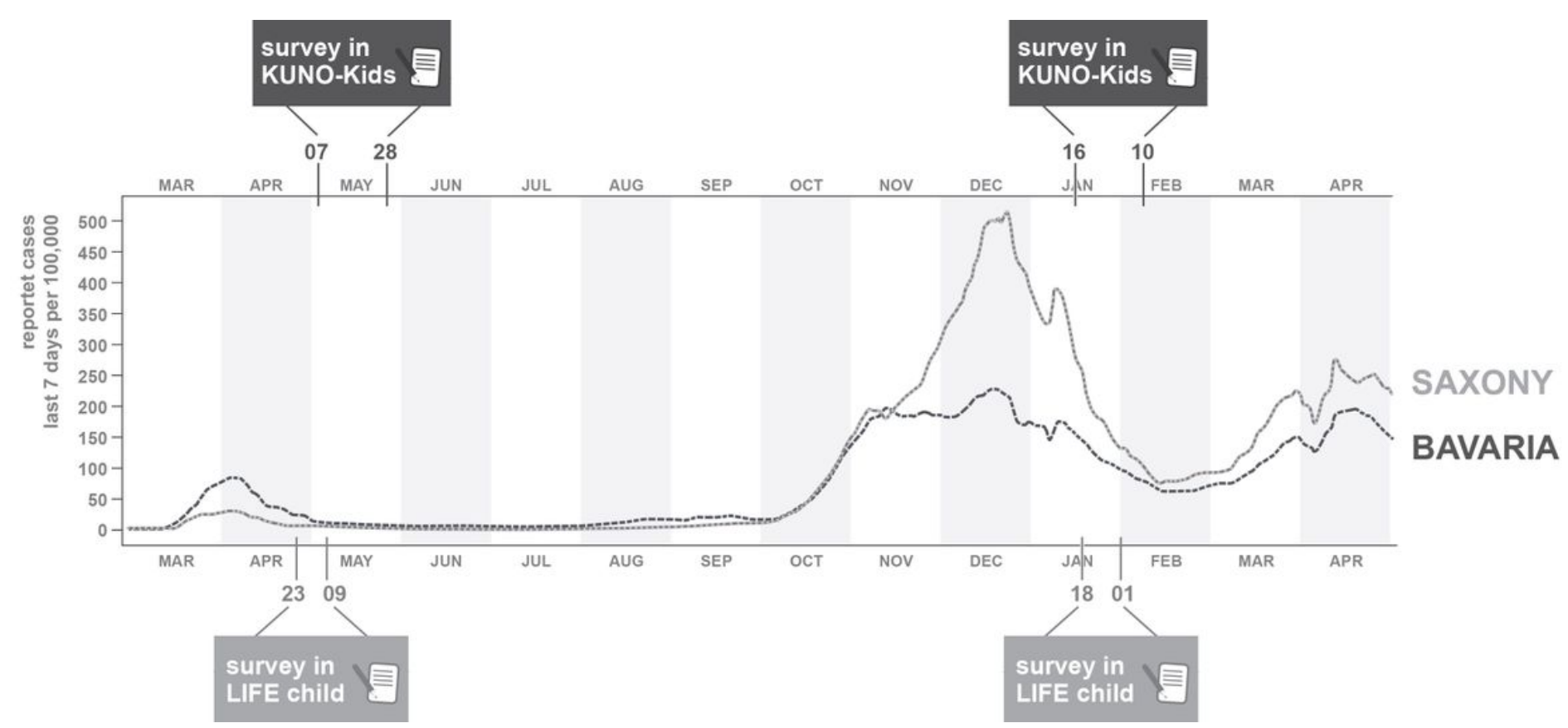

Figure 1

Course of COVID-19 incidence in Bavaria (for Regensburg) and Saxony (for Leipzig) and timing of online surveys. 
Regensburg

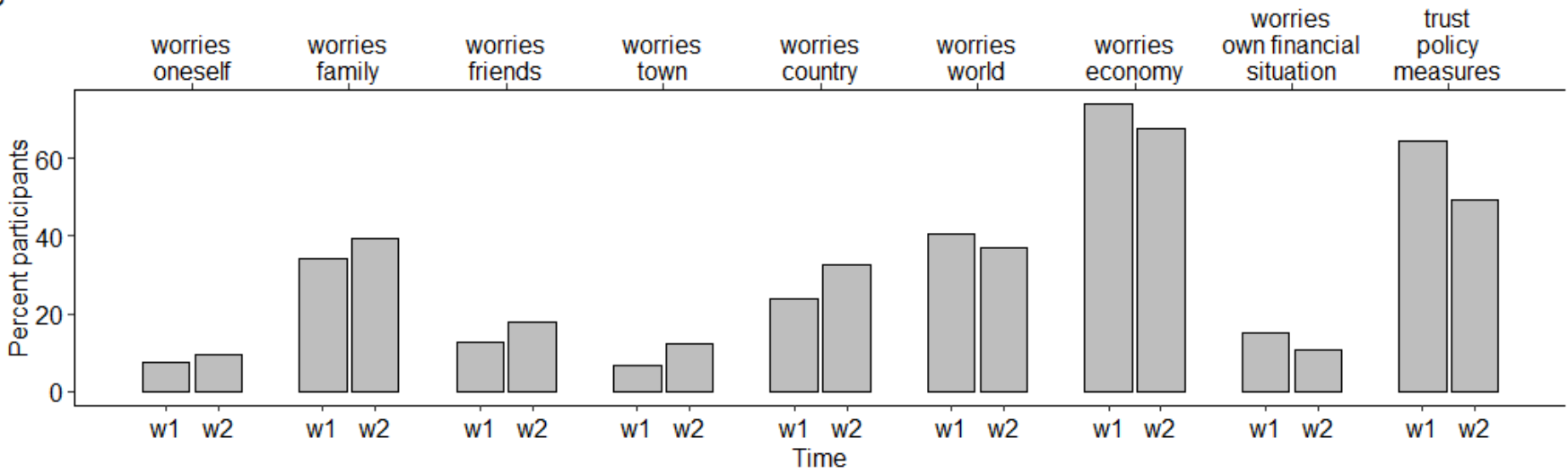

Leipzig

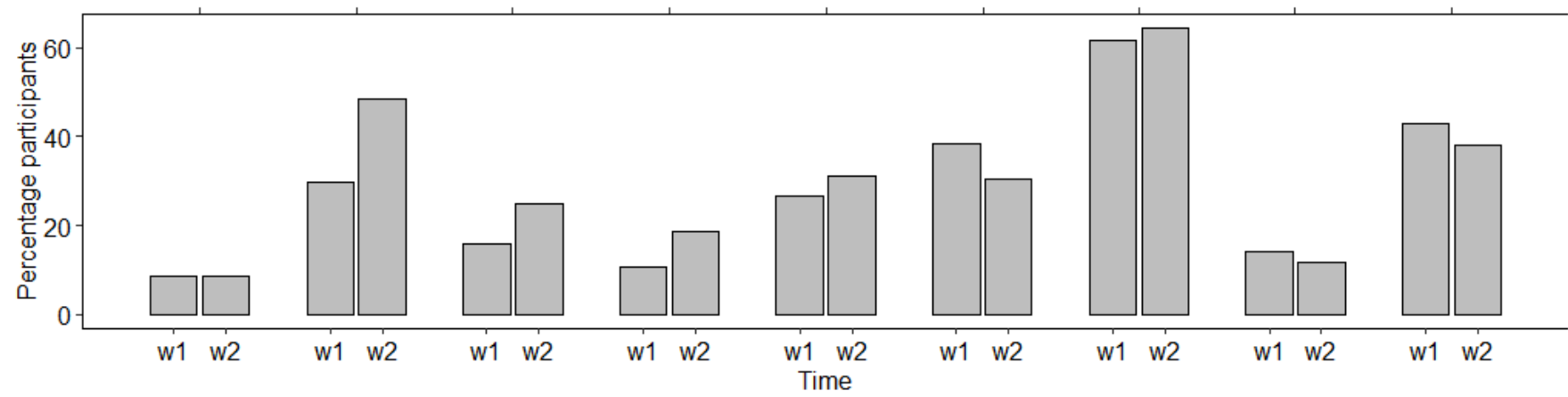

Figure 2

Percentage of COVID-19 related worries and trust in policy measures in Regensburg and Leipzig at wave 1 (w1) and wave 2 (w2). For clarity, only the percentages of participants indicating that they worry (or trust) "very much" or "extremely" are presented.

\section{Supplementary Files}

This is a list of supplementary files associated with this preprint. Click to download.

- Additionalfile1.pdf 